\title{
LOS DESARROLLADORES DE LIBROS APP INFANTILES Y JUVENILES: RADIOGRAFÍA, PERSPECTIVAS Y MODELO DE NEGOCIO
}

\author{
Neila Sanz Pilar* \\ Universidad de Salamanca \\ Araceli García Rodríguez ${ }^{* *}$ \\ Facultad de Traducción y Documentación. Universidad de Salamanca.
}

\begin{abstract}
Resumen: El mercado de literatura infantil y juvenil en España se ha mantenido en auge en las últimas décadas y ha sufrido un incremento exponencial desde la introducción de las TIC's y el desarrollo de contenidos digitales especialmente dirigidos a niños y jóvenes. Por ese motivo esta investigación pretende mostrar una breve radiografía de los desarrolladores de un determinado tipo de libros electrónicos, los libros aplicación, o enriquecidos, utilizando la terminología anglosajona, destinados a este público en España. Debido a la falta de estudios sobre este tipo de libros electrónicos en el subsector de la literatura infantil y juvenil en nuestro país, se ha aplicado una metodología exploratoria basada, por un lado, en la recopilación de fuentes de información, tanto primarias como secundarias, y por otro, en la obtención de respuestas de las empresas a través de una encuesta ordenada y sistemática de variables controladas. La finalidad es conocer las características intrínsecas que definen a estas compañías, analizar los cambios producidos en el modelo de negocio a través de la producción, la comercialización y la promoción de los libros aplicaciones; y delinear las perspectivas de futuro tanto de estas empresas como de los libros aplicaciones en el subsector de la literatura infantil y juvenil española, demostrando que son empresas jóvenes, compuestas por equipos interdisciplinares, que abogan por la renovación del modelo de negocio a través de la integración de formatos y soportes digitales, plataformas de venta online y herramientas Social Media 2.0.
\end{abstract}

Palabras clave: Mercado e industria editorial; desarrolladores de contenidos digitales; libros electrónicos; libros aplicación; libros enriquecidos; aplicaciones de lectura; literatura infantil y juvenil.

Title: APPLICATION DEVELOPERS AND APP BOOKS FOR CHILDREN AND YOUNG PEOPLE IN SPAIN: CHARACTERISTICS, PROSPECTS AND BUSINESS MODEL.

Abstract: The Spanish market of Children and Young people's Literature has been on the rise in recent decades and has undergone an exponential increase since introduction of ICT and the acquisition of digital contents which are dedicated to the children and young audience. For this reason, this research aims to show brief X-ray developers of a particular kind of ebooks, enhanced ebooks in Anglo-Saxon terminology, to set aside children and young people in Spain. Due to the lack of studies on these kinds of ebooks in the Children and Young people's literature in Spain, an exploratory methodology has been applied. On the one hand, it's based on the collection of primary and secondary sources of information, and on the other hand, an orderly and systematic survey of controlled variables has been created to obtain the answers from developers of enhanced ebooks. The purpose is to know the intrinsic characteristics that define its; to analyze the changes in the business model through the production, marketing and promotion of enhanced ebooks; and finally, to outline the future prospects these companies both application books in Spanish Children and Young people's literature subsector; showing that they are young companies, composed by interdisciplinary teams and advocating the renewal of the business model through the integration of digital media, online sales platforms and 2.0 Social Media tools.

Keywords: Publishing industry and market; digital content developers; eBooks; application books; enhanced ebooks; reading applications; children and young people's literature.

\section{INTRODUCCIÓN.}

La literatura infantil y juvenil (en adelante LIJ) es uno de los subsectores más relevantes de la edición que, desde su nacimiento como género específico, ha contribuido al crecimiento e innovación de la industria editorial a nivel internacional. Desde la introducción de las tecnologías de la información y la comunicación (en adelante TIC's) en el entorno de la edición, la LIJ ha acrecentado poco a poco su presencia y potencialidad y ha ido adaptándose de forma lenta, pero progresiva, a este nuevo mundo de la edición digital. ${ }^{1}$

Los libros electrónicos con contenido multimedia para niños y jóvenes están adquiriendo un papel relevante, tanto para la evolución e innovación del subsector LIJ, como para el crecimiento y desarrollo de la industria y el mercado

\footnotetext{
*neilasanz@usal.es

**araceli@usal.es
} 
editorial, sin olvidar, su imbricación en la industria de las TIC's y la transformación implícita en los hábitos de lectura del público infantil y juvenil.

Profesionales e investigadores, se están poco a poco aproximando a este tipo de productos aunque, todavía no exista un corpus teórico lo suficientemente amplio como para abordar todas las implicaciones que el desarrollo de este nuevo tipo de productos están produciendo en la lectura y en el sector editorial. ${ }^{2}$

En los últimos años estamos asistiendo a un enorme crecimiento de dos tipos de libros electrónicos, las aplicaciones de lectura y los libros aplicación, dos términos que se suelen utilizar indistintamente y que conviene matizar.

Las aplicaciones de lectura son, "programas informáticos que permiten la gestión de contenidos (...) y el acceso a los mismos, así como la interacción con el lector usuario, facilitando en la mayor parte de los casos la adaptación del contenido (...) para ser leído en un dispositivo móvil de lectura”3 y que integran las compras de varios libros en el mismo producto. Es el caso de Play Tales, Joy Tales, Booksy o Contoplanet.

Los libros apps son también programas informáticos pero ligados a la lectura de un título determinado y que se adquieren de forma independiente en las plataformas de distribución y venta. Es decir, que todas las aplicaciones de lectura incluyen libros apps, pero no todos los libros apps forman parte de una aplicación de lectura.

Aunque aparentemente parece que se está hablando de lo mismo, hay una pequeña diferencia. En el primer caso la misma aplicación permite el acceso a contenidos distintos, de este modo para acceder al libro "Los colores de Violeta" es necesario tener tanto la aplicación de PlayTales como la del propio cuento. En el segundo de los casos, las funcionalidades del título se activan directamente desde el propio contenido sin que éste se pueda separar de la aplicación como "Por cuatro esquinitas de nada" de Dada Company.

Este desarrollo se justifica tanto por la producción de libros app, "representando la edición digital un 11,2\% y en otros soportes, el 11,3\%" (PANORÁMICA DE LA EDICIÓN, 2012, p. 57) como por el compromiso de los desarrolladores, unas empresas que están innovando tanto en la creación de contenido como en su distribución y comercialización, adaptándose a las necesidades del público infantil y juvenil y a los requisitos de la industria y el mercado.

Por ese motivo, el objetivo fundamental de este trabajo es demostrar la transcendencia que tienen los desarrolladores de libros app infantiles y juveniles en el mercado de contenidos digitales dedicados a niños y jóvenes en España pero también:

- Observar las características de estas empresas y comparar su modelo de negocio con el tradicional.

- Descubrir sus mecanismos y métodos de producción, distribución y/o comercialización, promoción y marketing, así como la implicación de las TIC's en la forma de generar, distribuir y promocionar los libros app infantiles y juveniles.

- Conocer sus futuras líneas estratégicas y proyectos editoriales, la competitividad y el posicionamiento de libros app infantiles y juveniles españoles en el mercado global, así como el posible acercamiento y conectividad con los clientes y/o lectores gracias a las herramientas Social Media.

\section{METODOLOGÍA.}

Determinar la relevancia de estas compañías en el subsector LIJ, implica conocer el periodo de integración de las empresas en el mercado y los canales de distribución que utilizan para incorporarse al mismo, la producción y la promoción de los libros app, las propiedades de los productos resultantes y los mecanismos por los que llegan al público. Pero también, supone ahondar en la constitución de un modelo de negocio que refleja el paradigma que vive actualmente el mercado y la industria editorial y que puede servir como ejemplo de correcta adaptación a los cambios.

Para cumplir los objetivos previamente marcados, se decidió hacer un estudio sobre una muestra de empresas que cumplieran al menos dos de los siguientes criterios:

- El número de libros títulos que componían su catálogo (se tuvo en cuenta aquellos desarrolladores que contasen en su catálogo con un mínimo de dos libros app)

- La contribución de la empresa en la innovación de contenidos digitales (en función de los comentarios y críticas de sus títulos) 
- El prestigio de la empresa, valorando aquellas que hubiesen obtenido premios por su labor editorial o hubiesen participado en eventos relacionados con la LIJ

- Su presencia en la red a través de perfiles y páginas en redes sociales

A continuación se procedió a la selección de las mismas utilizando para ello blogs especializados en LIJ, tales como Literatura Infantil y Juvenil Actual o eBooks Infantiles, a través del directorio de la página web de Edita Interactiva ${ }^{4}$ y de un rastreo de fuentes de información a través de los metabuscadores Metacrawler y Carrot, marcando como palabras clave, combinadas por operadores booleanos, los términos aplicaciones, app, literatura infantil y juvenil, LIJ, contenidos digitales, infantil y juvenil, libro electrónico, eBook, feria del libro y premios.

El siguiente paso fue realizar la encuesta que debía enviarse a las empresas, compuesta por seis bloques y treinta y seis variables que explicamos de forma resumida a continuación.

Bloque I. Datos generales: La finalidad de estas constantes era conocer los datos básicos, con especial incidencia en la fecha de creación y la dirección física, que nos proporcionaba información sobre las comunidades autónomas que apuestan por la innovación en la edición digital. El resto de las variables eran necesarias para establecer contacto y conocer el medio de acceso a las empresas, pero no se han incluido en el análisis de resultados para mantener el anonimato en la formulación de respuestas, en atención a la Ley 15/1999, de 13 de diciembre, de Protección de Datos de Carácter Personal y el Código Internacional ICC/ESOMAR 2007, pero también porque dichos datos no aportaban un valor añadido al análisis de resultados.

Bloque II. Datos sobre organización y estructura: Conocer el número de trabajadores era vital para averiguar la tipología de las empresas. En lo que respecta al perfil profesional y académico de los trabajadores, eran fundamentales para conocer los cambios producidos en el modelo de negocio y comparar los perfiles emergentes con los de la industria editorial "tradicional", así como comprobar cuáles son los estudios que se adecuaban a las necesidades de los desarrolladores.

Bloque III. Datos sobre producción: El número de libros app era básico para averiguar su productividad, al tiempo que la constante de las edades nos permitiría disponer de datos sobre el lector al que se dirigen sus productos. Las variables relativas a los proyectos digitales y sus directrices, eran relevantes para saber si estas empresas tienen perspectivas de futuro y hacía que tipo de contenidos se dirigen. Asimismo, se requería información sobre la tipología de los sistemas y los dispositivos de lectura y por último el precio, fundamental para realizar una comparativa con el de los libros en papel.

Bloque IV. Datos sobre comercialización: Los canales de distribución responden a la instauración del comercio electrónico o e-Commerce y la influencia de las plataformas de distribución para la venta de productos que requieren de internet y el mundo digital. La variable de aplicaciones de lectura propias nos serviría por tanto para analizar si los desarrolladores amplían sus mecanismos de innovación o se ajustan a los productos tecnológicos creados por la industria de las TIC's.

Bloque V. Datos sobre promoción y marketing: Disponer de datos sobre las acciones promocionales permitiría averiguar si las empresas apuestan por desarrollar sus campañas de novedades, difusión o actualización a través de la red y si para ello, apuestan por las herramientas Social Media. Las cuatro variables relativas a herramientas Social Media nos posibilitarían igualmente conocer cuales utilizan y su finalidad y con ello comprobar la implicación de estas empresas en el entorno digital. No obstante, la promoción no sólo se lleva a cabo vía internet, sino también en el medio físico, por lo que era necesario saber si estas empresas participan activamente en eventos literarios y se comprometen con los agentes que componen la industria y el mercado editorial.

Bloque VI. Preguntas abiertas: Estas preguntas corresponden al análisis cualitativo, creado con el propósito de expresar las perspectivas presentes y futuras de los desarrolladores. La variable relativa a la potencialidad del mercado de lectores infantil y juvenil la utilizamos para comprobar si las empresas ven o no futuro en dicho mercado y, por lo tanto, en su razón de ser.

En lo que respecta a las constantes sobre los límites existentes y las soluciones las considerábamos esenciales para entender los problemas a los que hacen frente y establecer posibles soluciones que favorezcan el dinamismo y renovación del subsector LIJ. 
Asimismo, las cuestiones sobre la visión del mercado español nos permitirían obtener información sobre la perspectiva de producción, comercialización y promoción de libros app infantiles y juveniles a nivel global y comprender si la edición digital en España puede ser relevante.

El motivo de formular las variables de la influencia de las herramientas Social Media y la generación de debates en la red era delinear la conectividad de las empresas con sus clientes y/o lectores o con otras editoriales para favorecer tanto la venta de sus productos como los flujos de información del subsector. En último lugar, la pregunta sobre las próximas aplicaciones, se estableció para observar la continuidad y proyección de las empresas en la edición digital.

Finalmente se realizó el envío de la encuesta y la recolección de los datos, de forma automatizada a través del software $e$-Encuesta y de forma manual desde el correo oficial de la Universidad de Salamanca.

Las fuentes de información aportaron como resultados veintisiete empresas, de las cuales 4 fueron excluidas por no cumplir ninguno de los criterios definidos anteriormente. De las 23 restantes, 16 respondieron a la encuesta, y aunque hubiera sido interesante la participación de todas ellas, consideramos que el porcentaje de respuesta es suficientemente representativo como para llegar a unas conclusiones bastante aproximadas. Las que finalmente respondieron al cuestionario fueron: Chocosoft, Cream Ebooks, Genera Interactive, El Tarlá Frikids, Play Creatividad, Zapa Ebooks, Dada Company, Ilubuc, Magic Tales, Mother Tongue, Mr. Garamond, Pipilapps, Pixelmoon, Sandía Books, Sanoen y Tales Apart.

\section{ANÁLISIS DE RESULTADOS.}

Presentamos a continuación los resultados extraídos de los formularios respondidos por las dieciséis empresas participantes en la investigación.

\subsection{Datos generales: fecha de creación y localización geográfica.}

En lo que respecta a la fecha de creación aunque la primera empresa española, Play Creatividad, se fundó en 1997, no será hasta el año 2010 cuando observemos una evolución progresiva ascendente.

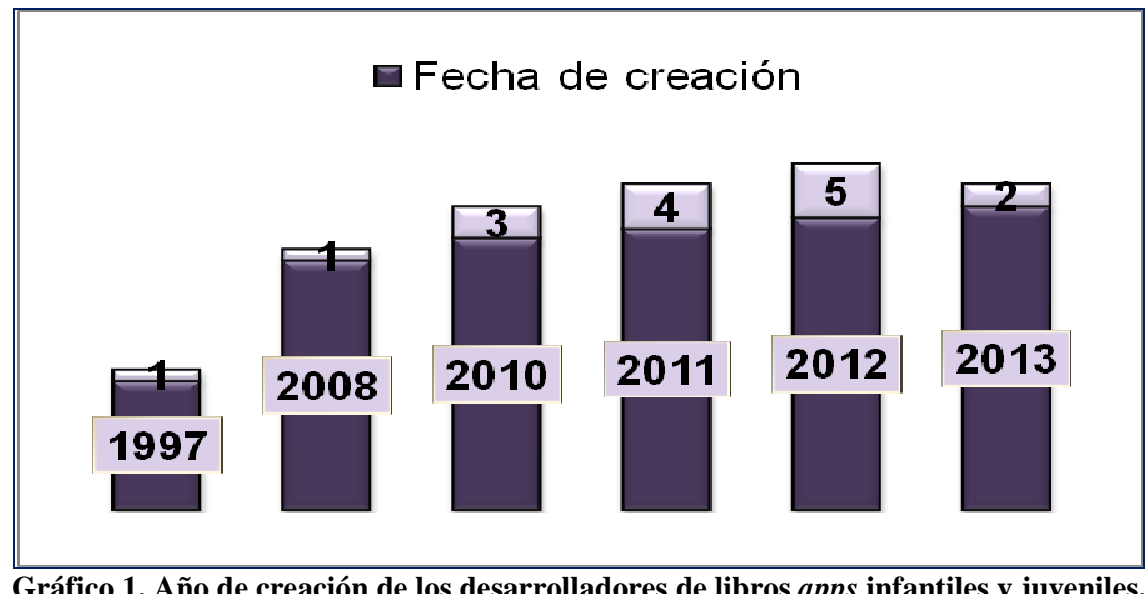

Este crecimiento entre los años 2010 a 2012 se explica por tres factores relacionados. El primero de ellos es la implantación e implementación de la edición digital en el sector; en 2010 la edición electrónica representó el 1,6\% de la edición, un porcentaje que creció en el 2011 hasta el 2,2\% y hasta el 5,4\% en el 2012 (PANORÁMICA DE LA EDICIÓN, 2012, p. 77).

El segundo factor está en relación con la consolidación de los dispositivos de lectura (tablets, móviles, smartphones...) ya que el aumento progresivo en la oferta y demanda, han favorecido el crecimiento de las ventas de libros como aplicaciones y la ampliación del mercado a esta nueva forma de distribución de contenido editorial.

Por último, hay que tener en cuenta los progresivos cambios efectuados en los hábitos de lectura en niños y jóvenes desde la inclusión de los dispositivos móviles y la oferta de títulos en digital, ya que como se recogen en los informes de lectura, "un 50\% de los menores de 10 a 13 años lee en soportes digitales. [...] En 2011 un 3,6\% leía en ebook/tablet y en 2012 un 4,4\% [...].” (HÁBITOS DE LECTURA, 2012, p. 137). 
En cuanto a la distribución geográfica, el $63 \%$ de los desarrolladores se sitúan en la comunidad de Cataluña, el $19 \%$ en la de Madrid y con un 6\% se incluyen las comunidades de Andalucía, Castilla y León, Castilla La-Mancha y País Vasco.

Además de la mayor tradición en edición LIJ en Madrid y Cataluña, hay que añadir que estas comunidades autónomas han apostado desde el principio por la edición digital, pues desde 2010, Cataluña condensa el $41 \%$ de los títulos editados y la Comunidad de Madrid el 35,7\%, sumando entre ambas comunidades el 76'7\% de la oferta. Lo mismo ocurre con el número de ejemplares editados, Cataluña alberga el 49\% del total y Madrid el 42,6\%, seguida por País Vasco (3,5\%), Castilla y León (1,8\%), Comunidad Valenciana y Galicia $(1,3 \%)$ y Andalucía (0,5\%). (LOS LIBROS INFANTILES Y JUVENILES, 2012, p. 13-14).

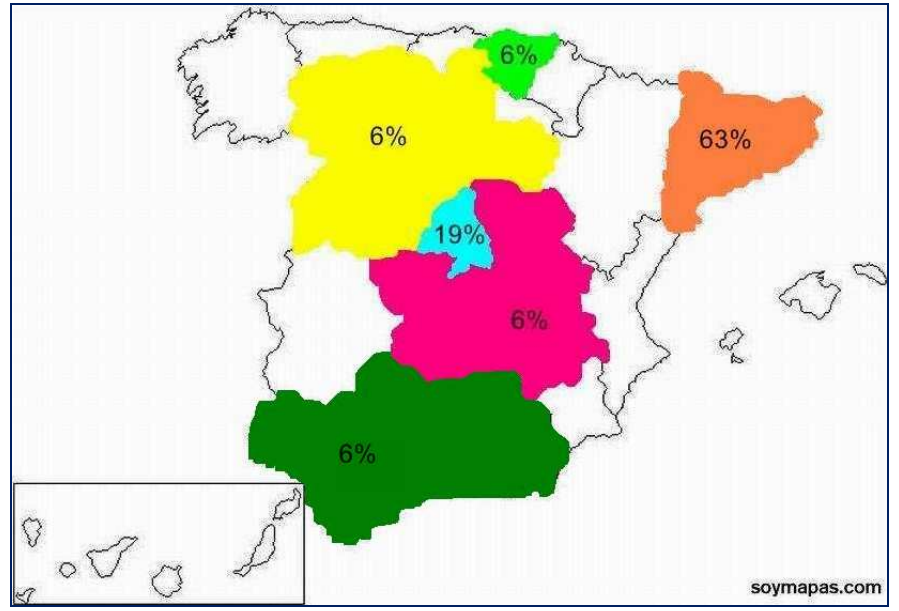

Figura 1. Mapa de localización de los desarrolladores de libros app infantiles y juveniles.

\subsection{Organización y estructura de las empresas.}

La organización y estructura de las empresas permite conocer las características intrínsecas y su tipología representativa a través del número de trabajadores y el perfil profesional y académico de los mismos.

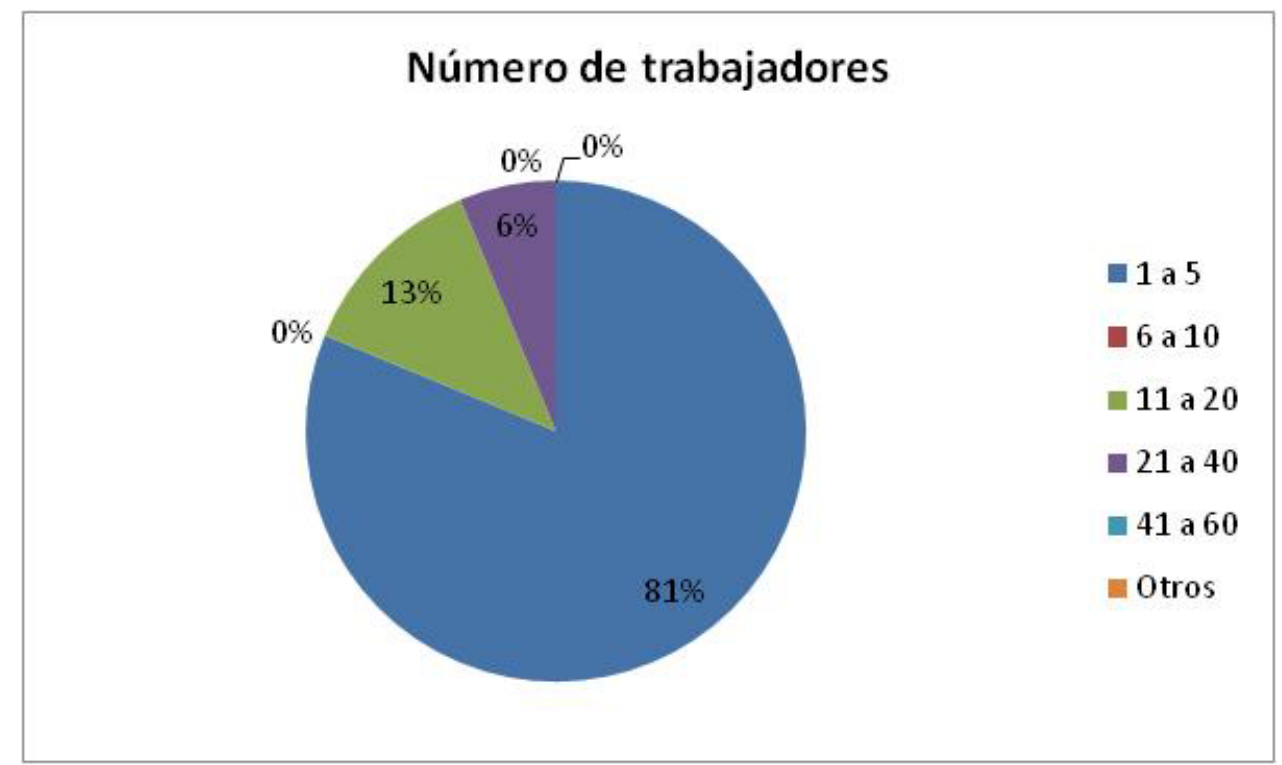

Gráfico 2. Número de trabajadores.

Por lo que se refiere al número de trabajadores, se observa que el $81 \%$ de los desarrolladores son microempresas, mientras que un $19 \%$ son pequeñas empresas no existiendo aún en el mercado medianas y grandes compañías que se dediquen en exclusiva al desarrollo de libros app infantiles y juveniles. Estos datos son 
diametralmente opuestos a los que nos ofrece la edición en papel en la que la oferta se encuentra concentrada en unas pocas y grandes empresas que controlan más del $60 \%$ del mercado y en la que el peso de las empresas pequeñas es minoritario.

Con respecto al perfil profesional, la tipología de puestos de trabajo y funciones desempeñados, los perfiles más frecuentes, corresponden a la categoría "otros", que no pertenecen al mercado laboral editorial tradicional; frente a los puestos de director, editor e ilustrador y en menor medida los de escritor, traductor y corrector literario, todos ellos afines a la industria editorial clásica. ${ }^{5}$

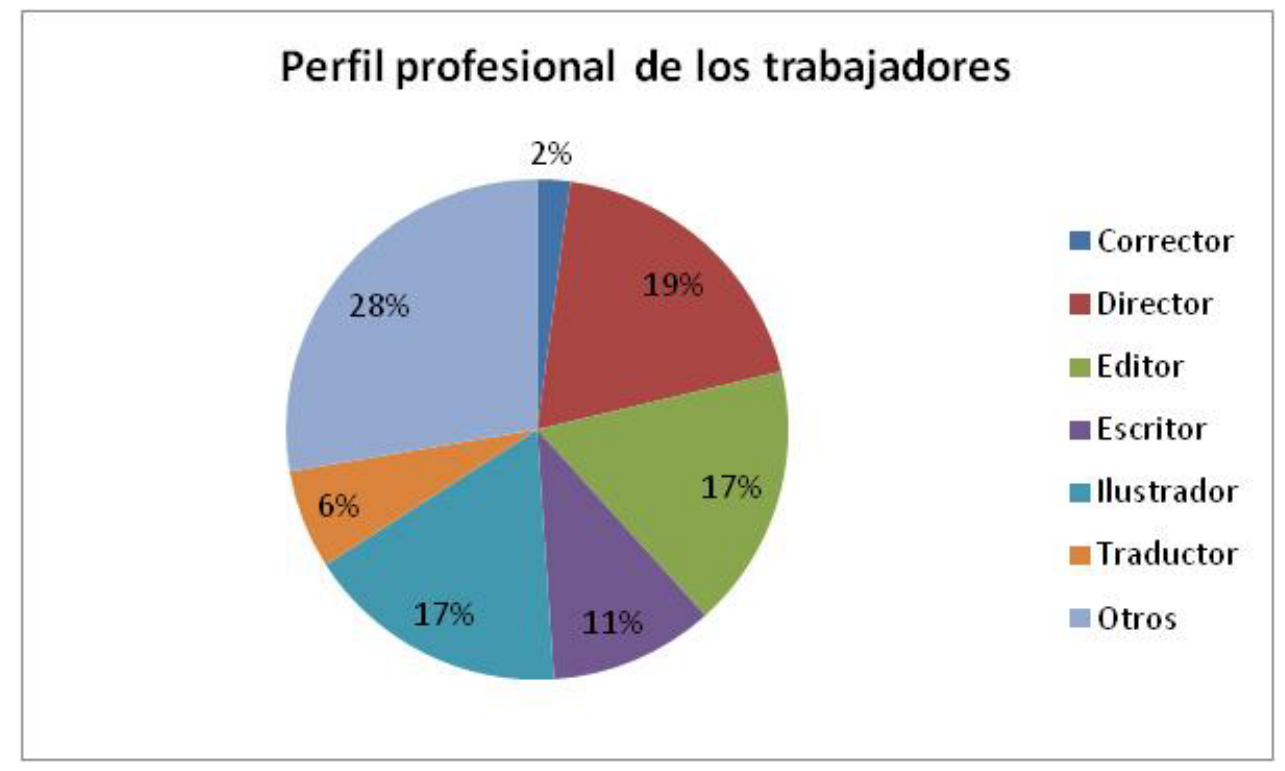

Gráfico 3. Perfil profesional de los trabajadores.

En lo relativo al apartado "otros" perfiles, de ese $28 \%$ incluido en la categoría, el mayor porcentaje corresponde al puesto de programador, seguido por el de community manager, comercial, gestor de información y otros. Por detrás, se sitúan los encargados de medios de comunicación, desarrollador web, administrativo y servicio técnico. El $11 \%$ correspondiente a la opción "Otros" recoge los datos aportados en las preguntas abiertas por cuatro de las empresas analizadas que mencionan los puestos de locutores, producción sonora, diseñador y diseñador de aplicaciones móviles.

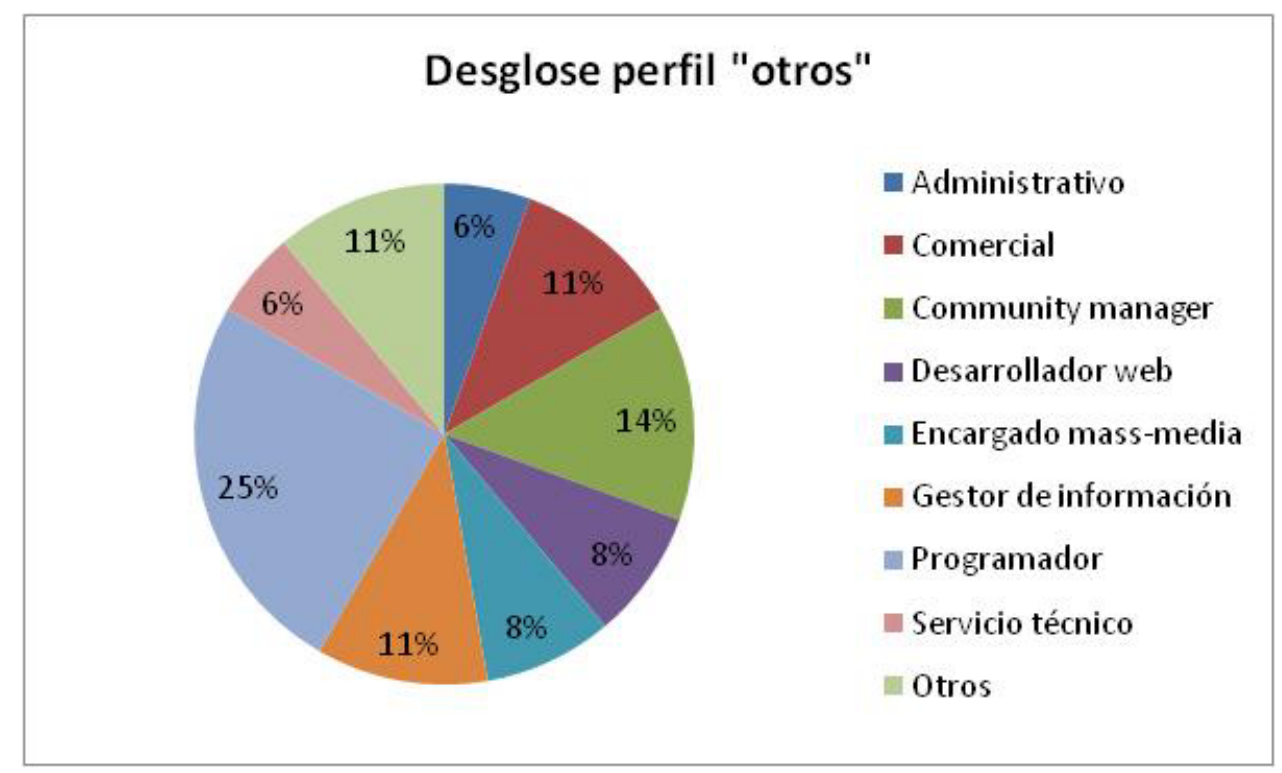

Gráfico 4. Perfil profesional de los trabajadores (Otros). 
La creación e integración de estos puestos de trabajo y funciones se vincula, por tanto a: la implementación de internet y las TIC's en las empresas, como es el caso de los puestos de programador, community manager y diseñador de aplicaciones móviles, que no tenían cabida en el mercado laboral editorial tradicional porque se originan exclusivamente, alguno de ellos, con la edición digital; a la inclusión de dispositivos de lectura que permiten integrar contenidos multimedia; a la implantación de la lectura social y la influencia de las redes sociales sin olvidar, la incorporación de productores de sonido y locutores, ya que parte del contenido multimedia está en relación con la narración oral y la integración de música.

A la hora de definir las características y estructura de una compañía de este tipo, es necesario conocer también la formación académica de los trabajadores, las carreras y los estudios que han cursado.

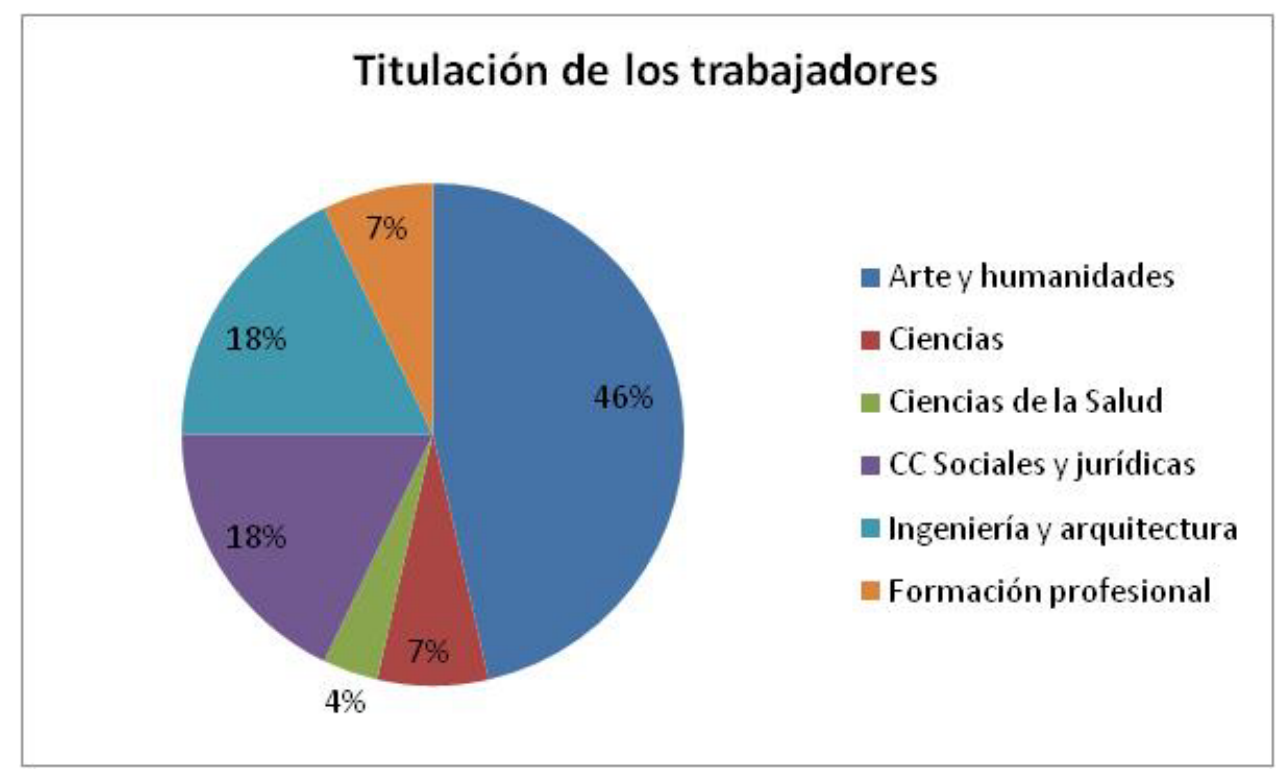

Gráfico 5. Formación académica de los trabajadores.

Como se observa, las ramas universitarias con mayores porcentajes son Arte y Humanidades, Ciencias Sociales y Jurídicas, Ingeniería y Arquitectura seguidas por Ciencias y Formación profesional y, en último lugar, la rama de Ciencias de la Salud.

Si bien se comprueba que los perfiles profesionales están tendiendo a la inclusión de técnicos en programación, informática y diseño de aplicaciones, llama la atención que la formación académica preferente proceda de Arte y Humanidades, un dato que puede derivar del hecho de que sea en estas disciplinas en las que se pueden adquirir conocimientos sobre literatura, literatura infantil y juvenil, ilustración, edición, etc. Sin embargo, el gráfico demuestra que, poco a poco, se va contando con personal cualificado en las ramas de Ingeniería y arquitectura y CC. Sociales y jurídicas, pues de estas disciplinas se forman técnicos en TIC's, marketing digital y gestión de información, funciones que encajan a la perfección dentro de la evolución del modelo de negocio editorial actual.

\subsection{Producción.}

En lo que se refiere al desarrollo de proyectos digitales, quince de las dieciséis empresas encuestadas van a llevar a cabo nuevos proyectos y sólo una de ellas va a destinar sus esfuerzos, por un lado, a perfeccionar los libros app ya editados, renovando los requisitos técnicos y de contenido y por otro lado a participar en proyectos colaborativos con otros desarrolladores y editoriales.

En cuanto a los datos totales de producción, doce de las empresas tienen de uno a cinco libros app en su catálogo, dos de seis a diez títulos, una contiene de once a quince títulos y en un solo caso nos encontramos con un catálogo formado por entre 26 y 30 obras.

Se puede afirmar por tanto que, la mayor parte de los desarrolladores españoles poseen un catálogo pequeño, derivado de su juventud y resultado de su incipiente introducción en el mercado, y que sólo aquellas creadas antes del 2010 han alcanzado una cierta estabilidad con una colección formada por más de 10 títulos. 
Aunque el número de aplicaciones todavía es pequeño, puede ayudar a acrecentar la edición digital dentro del subsector LIJ en España, teniendo en cuenta que la oferta de libros electrónicos ha experimentado desde 2008, y especialmente a partir de 2010-2011, un enorme crecimiento.

Junto a los datos generales de producción es fundamental conocer las líneas de dirección de los proyectos digitales, es decir, a qué tipo de género literario y a que etapa lectora están dirigiendo su producción.

Según los datos de la encuesta, los proyectos digitales actuales son muy diversos y abarcan distintos contenidos, entre los proyectos se encuentran álbumes ilustrados, cómics, productos educativos sobre idiomas, trastornos de aprendizaje o lectoescritura, adaptaciones de cuentos tradicionales, leyendas, obras de teatro, audiocuentos $\mathrm{y}$ aplicaciones que integran bandas sonoras, efectos de sonido o narración oral.

Durante los primeros años de producción, lo más habitual ha sido adaptar cuentos tradicionales y según las compañías han ido incurriendo en el mercado y han visto aumentar su demanda, se han ido incorporando proyectos de temática innovadora. No obstante, los géneros de la LIJ siguen siendo los mismos y el contenido, tanto ilustraciones como texto, siguen siendo los elementos principales.

El valor añadido de la inclusión de objetos multimedia (música, juegos, narración oral, vídeos...) se debe a la transformación en la forma de leer y comprender el texto, ya que ayudan y complementan la historia y además favorecen la interacción de los niños y los jóvenes con el objeto, fomentan la imaginación, amplían su desarrollo cognitivo y mejoran sus habilidades mnemotécnicas.

Debido a su estrecha relación con los contenidos, es necesario conocer también hacia que etapas lectoras se dirigen los esfuerzos de las diferentes empresas.

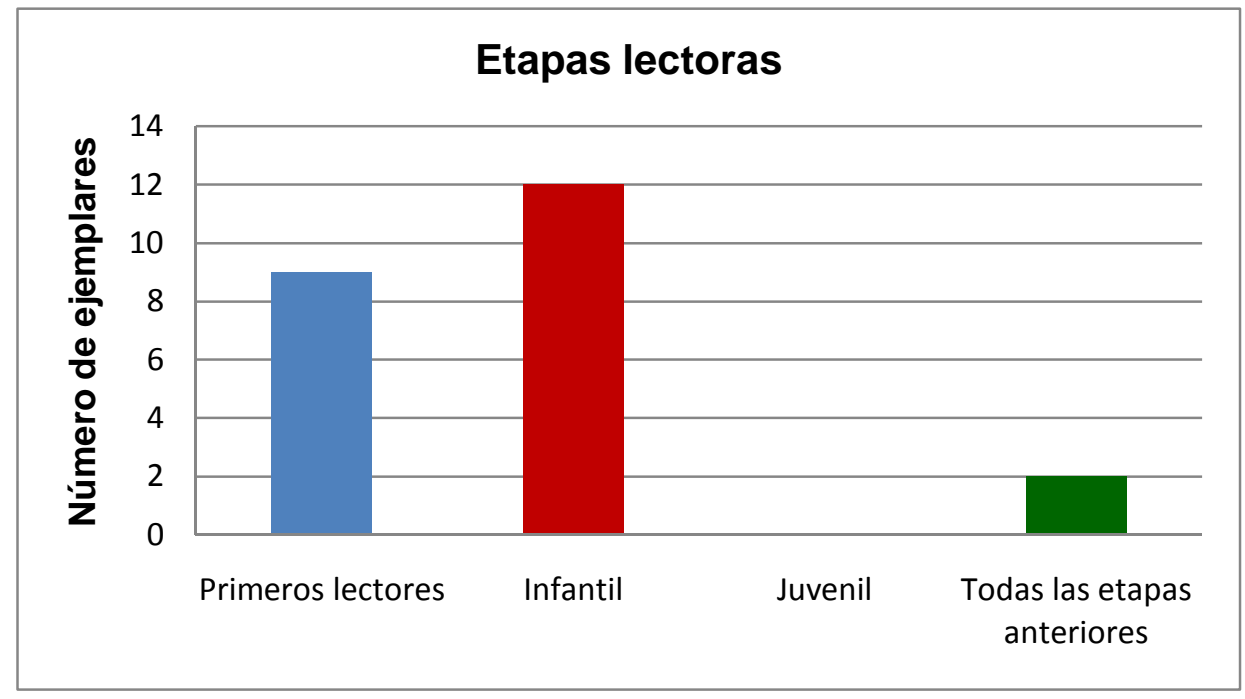

Gráfico 6. Etapas lectoras.

Nueve de las empresas participantes centran sus esfuerzos y sus prioridades en los primeros lectores ( 0 a 3 años), doce los destinan a infantil (5 a 11 años), dos crean sus libros para todas las etapas, incluyendo el juvenil (a partir de 12 años), existiendo cierta carencia de desarrollo de libros app para jóvenes.

Conocer el sistema operativo permite comprender de forma aproximada el software que requieren las aplicaciones para su descarga y visualización, así como comprobar las derivaciones de las TIC's en el modelo de producción editorial. 


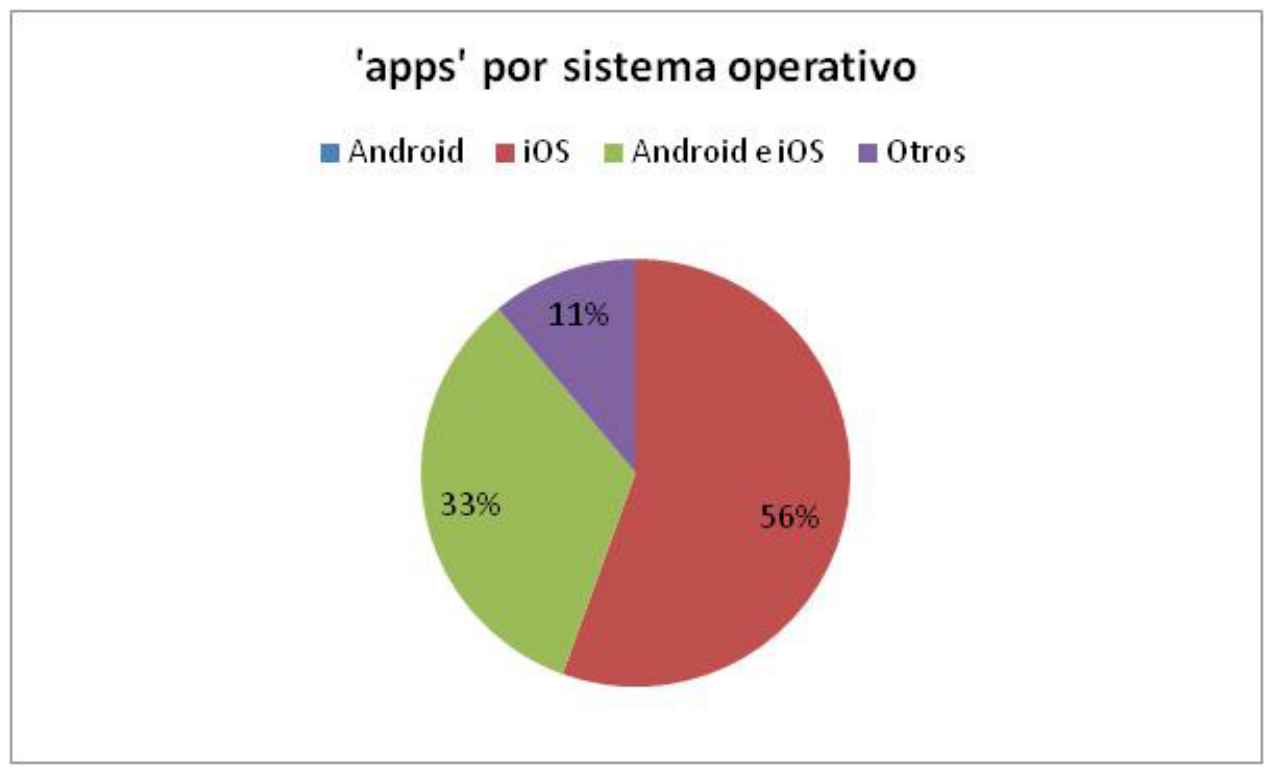

Gráfico 7. Sistemas operativos de los libros app.

El sistema operativo más utilizado es iOS, seis empresas responden que utilizan indistintamente tanto el sistema iOS como Android, ninguna utiliza Android en exclusividad y sólo dos desarrolladores desarrollan sus productos en otros sistemas como Windows y Mobi.

En estrecha relación con el sistema operativo se encuentran los dispositivos de lectura, es decir, los soportes físicos en los cuales se pueden descargar y leer los libros.

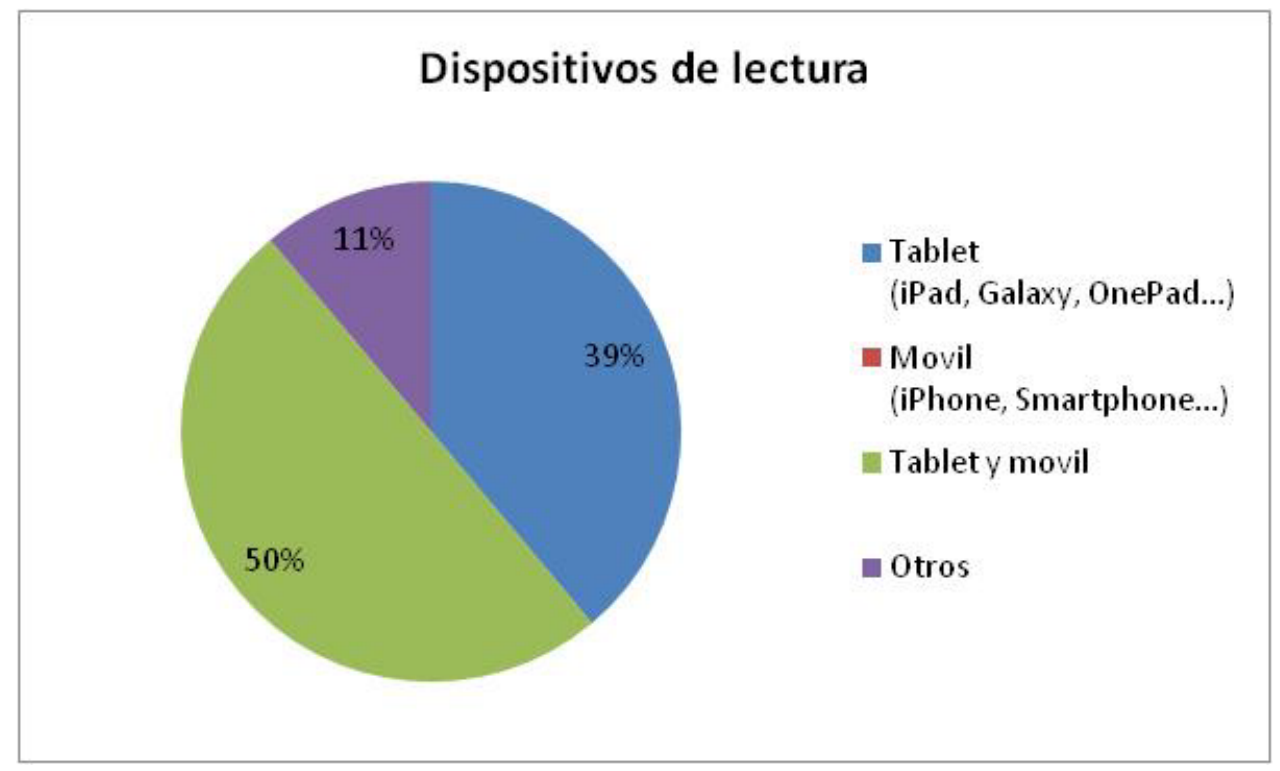

Gráfico 8. Dispositivos de lectura de libros app.

En general las empresas crean sus libros app para todos los dispositivos anteriores, siete para tablets y dos lo hacen para otros dispositivos, como ordenadores y Kindle Fire. Con respecto a la telefonía móvil, ninguna se dedica de forma exclusiva a crear libros para este tipo de dispositivo, si bien hay que tener en cuenta que se incluyen también dentro del porcentaje de todos los dispositivos anteriores al utilizar los mismos sistemas operativos.

En cuanto al precio de las aplicaciones, varía entre los 2,5 y los 3 euros, seguido muy de cerca de aquellos títulos que cuestan entre 1,5 a 2 euros; en menor medida, se encuentran los gratuitos, los de 1 euro y en último lugar aquellos con un valor entre 3,5 a 4 euros. 
Podemos afirmar por tanto que los libros app infantiles y juveniles son productos baratos y asequibles, cuyo precio medio oscila entre 1,5 a 3 euros, un coste relativamente bajo frente a los libros infantiles y juveniles, en papel en su edición rústica (los más baratos del mercado editorial español), que suele estar entre los 8 y 10 euros o entre 15 o 16 euros en el caso del álbum ilustrado y los libros informativos.

Esta bajada de precios, que supone una permutación en la producción y, por tanto, en el modelo de negocio, está en relación con tres factores. El primero de ellos es que la LIJ siempre ha sido el subsector del mercado editorial con los precios más bajos. El segundo factor es la competitividad del subsector LIJ dentro del mercado editorial, "la presencia de los títulos infantiles digitales en plataformas de distribución, librerías o webs es mínima frente a los miles de títulos disponibles para adultos”, GARCÍA RODRÍGUEZ, 2012, p. 148) y en tercer lugar, el criterio establecido por los distintos actores del mercado de que la edición digital ha de tener un precio inferior a la edición impresa.

\subsection{Comercialización y distribución.}

Los canales de distribución son los medios que ofrecen al usuario el material en formato digital a fin de que el cliente cuente con todos los datos para decidir la adquisición de los títulos que está consultando.

Las empresas pueden utilizar diferentes canales de comercialización y en este caso las dieciséis empresas participantes optan mayoritariamente por las plataformas genéricas, sólo dos utilizan su propia plataforma (Playtales y Byeink), una comparte plataforma con otras editoriales (Playtales) ${ }^{6}$, una efectúa las ventas directamente desde su web y sólo otra lo hace desde otras plataformas.

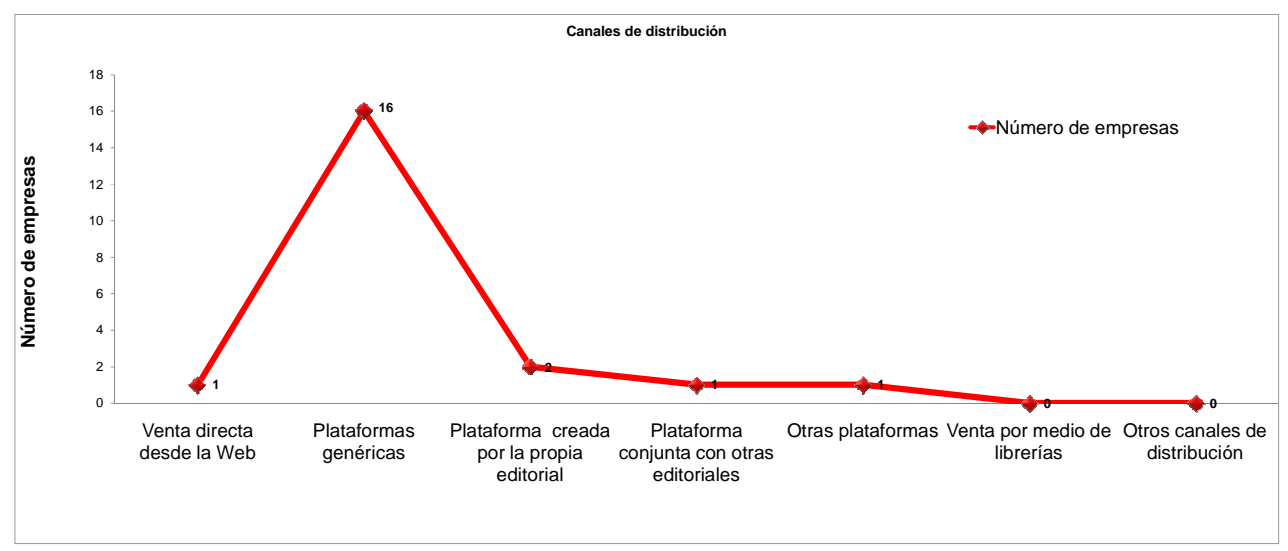

Gráfico 9. Canales de distribución de libros app.

Por lo que se refiere a las plataformas genéricas, las dieciséis empresas utilizan la plataforma iTunes, siete la plataforma Amazon, seis venden los libros app a través de Google Play, tres lo hacen a través de Troa y sólo una a través de Fnac, existiendo seis canales de distribución que no se utilizan para el fin de venta.

La mayor distribución en las plataformas iTunes y Google Play se debe a los sistemas operativos y los dispositivos de lectura para los que se desarrollan los libros app, ya que la plataforma iTunes está vinculada al sistema operativo iOS y los dispositivos de lectura iPad y iPhone, mientras que Google Play está vinculada al sistema operativo Android y a los dispositivos de lectura que contengan dicho sistema.

En el caso de Amazon, no podemos olvidarnos de que es el primer portal de comercio electrónico y con mejor cadena de suministro de contenidos digitales, incluyendo los libros app, del mercado internacional.

Por lo tanto, la mayoría de las empresas apuesta para la distribución de sus libros app por plataformas genéricas ya existentes, especialmente por las vinculadas a grandes compañías internacionales. No obstante, se comprueba que algunas deciden apostar por la innovación y crear sus propios canales de distribución, que, además, comparten con otros desarrolladores, estableciendo la colaboración en la venta de los libros app. 


\subsection{Promoción y marketing.}

El área de promoción y marketing se encarga de establecer contacto y afianzar la relación comercial con los clientes a través de diversos medios de comunicación, con la finalidad de informar y ofertar los productos que generan y ponen a la venta.

Todas las compañías encuestadas afirman llevar a cabo acciones promocionales y que se implican intensamente en las funciones de difusión, promoción y marketing. Por un lado, porque son las estrategias de venta y por otro, porque es la forma de acercar sus productos a los clientes, conocer sus perfiles y preferencias, permitiéndoles a su vez, innovar en la creación de aplicaciones y adecuarse a las necesidades potenciales de sus lectores.

La acción promocional que desempeñan se desglosa en dos vías, la inclusión de la promoción y el marketing en internet y el desarrollo de estrategias de promoción y marketing del mercado editorial tradicional.

Por lo que se refiere a la tipología de las herramientas Social Media utilizadas, los mayores porcentajes corresponden a las redes sociales, seguidas por los blogs, microblog, weblog y las páginas web. El siguiente puesto lo ocupan los boletines de noticias y los booktrailers y finalmente la sindicación de contenidos o RSS.

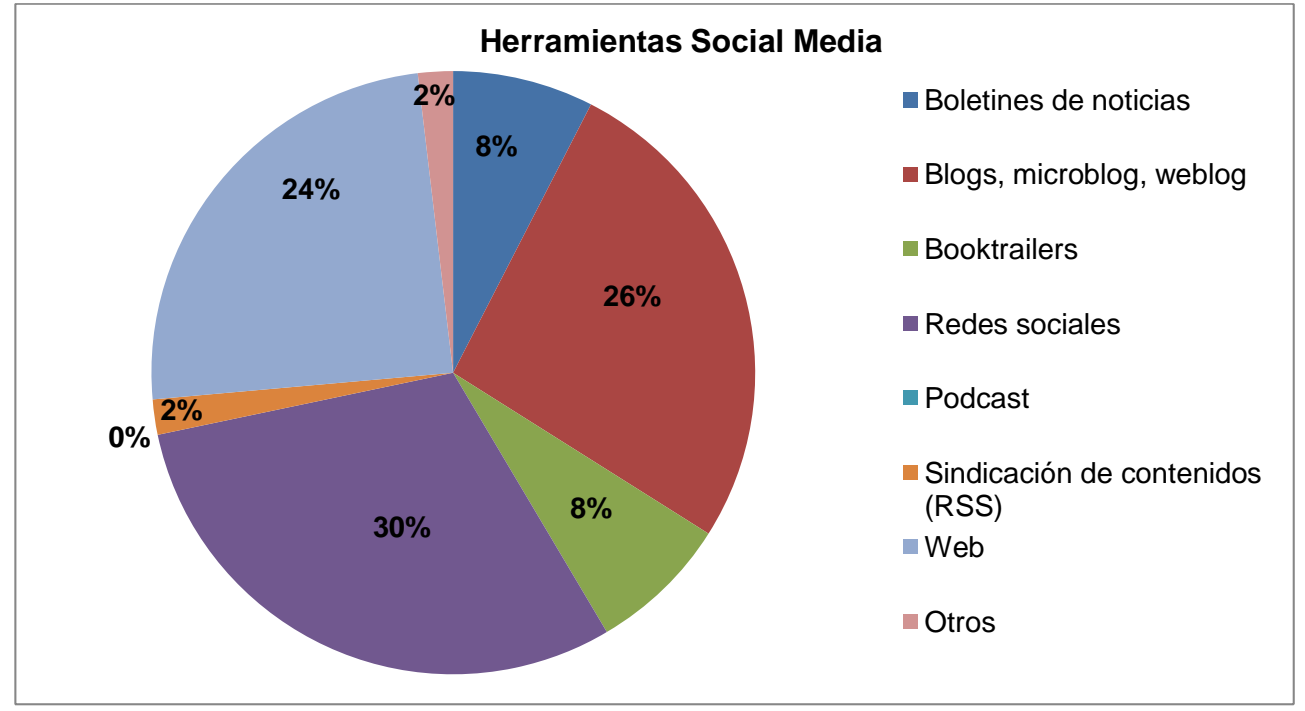

Gráfico 10. Herramientas Social Media utilizadas para la promoción.

Si nos detenemos en el análisis de las redes sociales utilizadas, observamos que la mayor presencia corresponde a Facebook y Twitter, seguidas por Pinterest, Linked In, Google Plus y otros. Como se deduce del gráfico, Myspace y la red profesional Xing no son utilizadas, quizá porque son redes que no se ajustan al perfil de los desarrolladores.

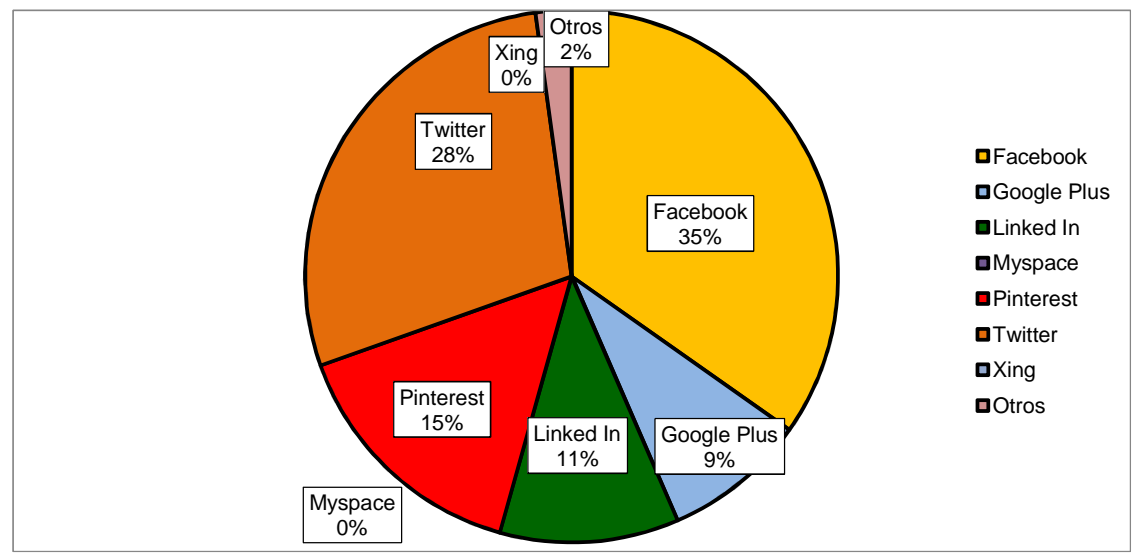

Gráfico 11. Redes sociales utilizadas para la promoción. 
Por lo tanto la preeminencia de difusión, promoción y marketing se desenvuelve en torno a Facebook y Twitter, lo que demuestra que "la omnipresencia de Facebook sigue siendo una constante. Twitter y Linkedin sigue con altos crecimientos [...] Facebook es conocida por casi la totalidad de los usuarios de redes. Twitter, Linked In y Google+ han aumentado progresivamente su conocimiento a través de los años [...] Facebook es la red social que tiene mayor dedicación de tiempo tanto en visitas al mes como horas dedicadas, seguida por Twitter y Youtube [...] Tuenti es la favorita en target 14-17” (INTERACTIVE ADVERSTISING BUREAU, 2013, p. 61). Éstas son las redes sociales que más se ajustan a las necesidades promocionales de las empresas como marcas y las que permiten una conectividad entre clientes y empresas más sencilla y eficaz.

Junto a las redes sociales, destacan también los blogs, microblog y weblog como herramientas Social Media. Los más utilizados son Wordpress y Tumblr, seguidos por Blogger. En lo que respecta a la opción otros, la respuesta es aportada por una única empresa y se refiere a la promoción en blogs especializados en literatura infantil y juvenil, es decir, creados por personas externas a la empresa pero con quienes se interactúa para la difusión de novedades de su catálogo.

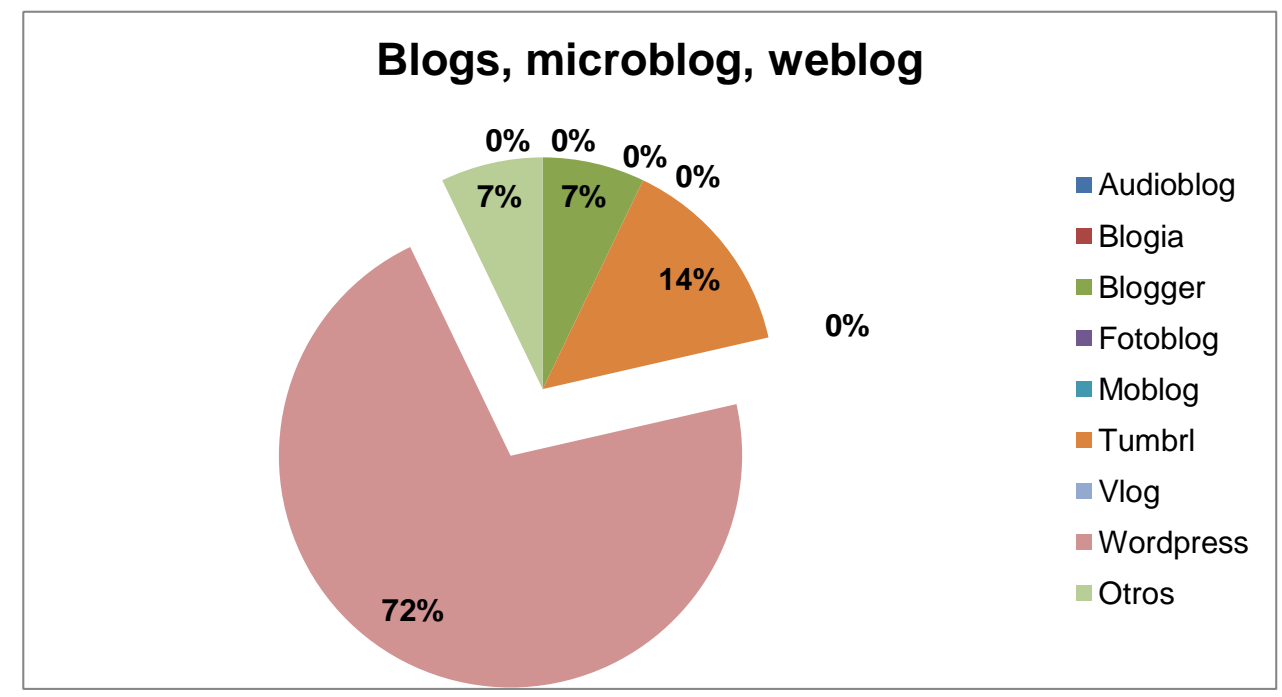

Gráfico 12. Blogs, microblog, weblog utilizados para la promoción.

La preeminencia de Wordpress y Tumbrl se debe a que el primero, además de sus funciones como blog, ejerce como gestor de contenidos, ampliando y aportando un valor añadido a la promoción, mientras que el segundo se tiene en cuenta sus características de microblogging, como servicio rápido e intuitivo.

Cabe preguntarnos ahora cual es la finalidad y el uso que las empresas realizan de las herramientas Social Media, una interrogante que resumimos en el siguiente gráfico.

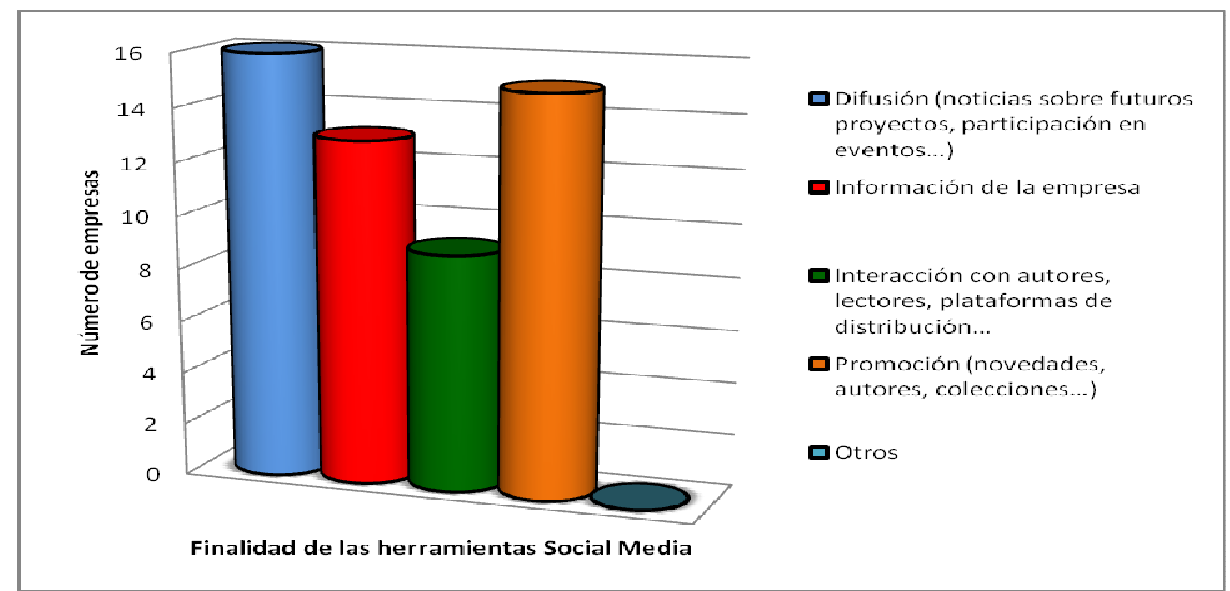

Gráfico 13. Finalidad de las herramientas Social Media utilizadas en la promoción. 
A tenor de los datos, se puede afirmar que en la estrategia de marketing priman la difusión y promoción de noticias sobre proyectos presentes y futuros, autores, colecciones y eventos, aunque llama la atención que sólo en nueve casos se mantenga contacto directo en red con los clientes, cuando éstos son la parte demandante de los productos que ofrecen y venden.

Como mencionamos anteriormente, existe una segunda vía de promoción y marketing relacionada con el mercado editorial, la asistencia y participación en eventos de literatura infantil y juvenil. En este caso, el $81 \%$ de las empresas encuestadas participan activamente en este tipo de eventos y demuestran un gran potencial internacional participando también en ferias internacionales como Bologna Children's Book Fair o Book Expo America (BEA).

\subsection{Perspectivas de futuro.}

Resumiremos en este último apartado las respuestas dadas por los participantes en la encuesta a las preguntas abiertas formuladas en torno a las perspectivas presentes y futuras del mercado de libros app para niños y jóvenes en España.

Ante la diversidad de opiniones para una misma pregunta, agruparemos aquellas contestaciones unánimes expresadas de forma divergente en una única respuesta.

\section{¿Considera que los lectores infantiles y juveniles son un mercado potencial e interesante para el desarrollo de libros app?}

La respuesta ha sido positiva al $100 \%$. Las causas de ser un mercado potencial, son la facilidad de uso de los dispositivos de lectura al ser nativos digitales ${ }^{7}$, la atracción que los niños y jóvenes sienten por la tecnología, la paulatina integración en los hogares de los dispositivos de lectura y la adquisición de los libros app por parte de los padres que observan en éstos las posibilidades de fomentar, o seguir fomentando con valor añadido, los hábitos de lectura de sus hijos.

¿Cuál cree que son las barreras para que la adquisición por compra de libros app infantiles y juveniles no haya alcanzado el desarrollo esperado en España?

Los encuestados exponen que las principales barreras son la falta de promoción y divulgación mediática; la falta de información y experiencia de consumo de contenidos digitales por parte de la sociedad o la incompatibilidad de los formatos.

Junto a estas barreras, se añaden la reticencia de la propia industria editorial para apostar firmemente por la edición digital y la integración de contenido multimedial, la desconfianza en el comercio electrónico o e-Commerce por parte de los clientes; la diversificación de la oferta de contenidos digitales y el aumento de los impuestos en el sector por el contexto económico actual.

Podemos afirmar por tanto que la ralentización en la edición y compra de libros app en España se debe por un lado a factores intrínsecos a la propia industria editorial que debe invertir más tiempo y recursos, tanto económicos como humanos en la edición digital, y al mismo tiempo hacer frente a campañas de promoción y marketing planificadas y estructuradas en torno a las herramientas Social Media.

Por otro lado, existen factores externos como son los precios y los requisitos técnicos de los dispositivos de lectura, el contexto económico que favorece o impide el desarrollo e innovación de la industria y el mercado a través de la oferta y la demanda y por último, la falta de confianza en la compra a través de la red.

\section{¿Cuál cree Vd. que pueden ser las posibles soluciones para aumentar su desarrollo?}

Las soluciones más factibles comienzan por crear alianzas colaborativas entre las diversas empresas del sector, así como desarrollar y gestionar una marca conjunta que facilite la comercialización y el marketing, estableciendo cambios en los modelos de promoción y difusión, apostando por el crossmarketing y el posicionamiento internacional.

También es indispensable innovar e investigar en contenidos digitales con la finalidad de aumentar y mejorar su calidad, apostando firmemente por los formatos abiertos para la compatibilización entre distintos sistemas operativos y dispositivos de lectura y promocionando ampliamente el uso de estos dispositivos en las aulas y las bibliotecas.

En cuanto a los editores, es necesario educar a los productores en la integración de contenido multimedia y en la necesidad de apostar por el desarrollo de colecciones, así como acordar la reducción de libros app gratuitos a un máximo de contenidos (prototipos). 
Por último, es necesario fomentar las ayudas y subvenciones públicas que permitan la creación de empresas en este sector para afrontar la competitividad en el mercado global, lo que implica indirectamente regresar a los valores anteriores del IVA cultural (4\%), así como afianzar la legislación antipiratería.

Por tanto, las soluciones a los factores externos que mencionábamos en la pregunta anterior son rebajar el coste de los dispositivos de lectura y apostar por los formatos abiertos que permitan la compatibilización de requisitos técnicos entre los diversos sistemas, mejorar el contexto económico y legislativo para favorecer la innovación en el sector, reducir las tasas impositivas y aumentar las subvenciones, así como llevar a cabo políticas de difusión de dispositivos y contenidos digitales entre la población.

En lo que respecta a los factores internos, las soluciones que plantean son la reducción de libros gratuitos a un determinado prototipo para dar salida al resto de la oferta, crear estrategias de colaboración entre las empresas del sector para consolidar la marca, favorecer la integración de contenido multimedia a fin de innovar y renovar el mercado, así como cambiar los modelos de promoción, comercialización y marketing, adecuándose a las TIC's.

En cuanto a la visión que perciben las empresas del mercado e industria de las aplicaciones en España en comparación con otros países, cabe señalar que los desarrolladores han confrontado el mercado español con el mercado más boyante y en constante evolución de la actualidad, el mercado norteamericano.

Es necesario realizar un pequeño inciso para comprender por qué el mercado estadounidense es el modelo de negocio ejemplar. Los últimos estudios llevados a cabo en el país demuestran el crecimiento de esta tipología de libros "in march 2012, the 25 billionth app was downloaded from Apple's App Store. There are currently more than 500,000 apps in the App Store [...]" (KOBO.The Children's Digital Book Market, 2013, p. 10) debido a la intensa labor de los desarrolladores y a que existe público que demanda este tipo de productos. En Norteamérica los dispositivos de lectura están ampliamente consolidados en todos los ámbitos de la sociedad y es habitual que la gente realice sus lecturas en soportes digitales, por lo que es lógico que las empresas españolas tomen como referencia este modelo.

Los desarrolladores de libros app infantiles y juveniles en España consideran que existe un gran número de pequeñas empresas creativas e innovadoras que, pese a ser un mercado incipiente caracterizado por un bajo nivel de madurez, tienen gran potencial y ofrecen calidad.

Sin embargo, dos de los mayores problemas a solventar son, por un lado, la falta de capacidad de proyección en el extranjero para hacer frente a la competitividad, cuya solución pasa por la adaptación de las editoriales tradicionales al cambio que han supuesto la introducción de las tecnologías y la implantación de los contenidos digitales multimedia; y por otro lado, la existencia de una oferta de libros app gratuitos con la que es difícil competir si la sociedad no está concienciada del esfuerzo que conlleva crearlas.

¿Considera que el mercado e industria de aplicaciones en España es capaz o puede ser capaz de alcanzar una importante relevancia en edición digital?

Unánimemente alegan que se puede alcanzar relevancia en edición digital no sólo a nivel nacional sino también a nivel internacional. Para lograr estos propósitos, las empresas tienen que ser capaces de aumentar su catálogo y publicar productos novedosos y de calidad, al tiempo que las editoriales clásicas deben apostar por las tecnologías y los contenidos digitales multimedia si quieren competir en el mercado global.

En general, la sensación que transmiten es positiva, opinan que hay mucho talento y que el idioma favorece su expansión en los países hispanoamericanos, pero inciden en las problemáticas que subyacen como son la necesidad de abrirse a nuevos formatos y modelos de negocio, visibilizar la producción o actualizar contenidos, requisitos indispensables en un mercado en constante evolución que requiere cambios constantes para fomentar el emprendimiento y la competitividad.

¿Cómo considera Vd. que influye la web y las distintas herramientas 2.0 en la comunicación y marketing de las aplicaciones infantiles y juveniles que desarrolla su empresa?

Los encuestados especifican que las herramientas 2.0 son un punto de encuentro que permiten conocer la opinión directa de los clientes, interactuar con ellos, vender y llegar a las comunidades afines a nivel global, aumentando los flujos de interés y comunicación y por tanto que son pilares básicos e imprescindibles para desarrollar las campañas de promoción y distribución. 
Exponen también que son esenciales para contactar con otros desarrolladores y participar en proyectos de colaboración, producción, distribución o promoción, pero también que deben convivir con los medios de comunicación y promoción offline, ya que siguen siendo vitales para contactar con los clientes y conocer las novedades del subsector LIJ.

\section{¿Participa activamente en las conversaciones generadas en la red con sus clientes y/o lectores?}

El 80\% de los desarrolladores encuestados responden de forma positiva frente a un $20 \%$ que no participa en las conversaciones generadas en la red. De las refutaciones afirmativas, y ante la pregunta ¿Con qué frecuencia participa en las conversaciones?, el $67 \%$ de las empresas participan en los debates generados en red diariamente, lo que implica una gran conectividad con los clientes y/o lectores.

La participación se realiza principalmente a través de la red social Facebook, pero también en blogs especializados en literatura infantil y juvenil. Asimismo, añaden que esa participación se hace efectiva a través del servicio de customer y support.

\section{CONCLUSIONES.}

Podemos deducir que el prototipo de los desarrolladores de libros app infantiles y juveniles españoles es el de una empresa joven, todavía en expansión; de pequeño tamaño, compuesta por equipos multidisciplinares procedentes del mundo editorial, las tecnologías de la información y la comunicación e internet; y que se afinca principalmente en Cataluña y Madrid.

No obstante, parece evidente que nacerán nuevas empresas y que las ya existentes consolidarán sus catálogos para abarcar tanto el mercado español como el internacional, adaptándose a la perfección a las nuevas necesidades de la Sociedad de la Información. Se deriva de esta primera conclusión la innovación en el sistema productivo, pues no sólo afecta al contenido sino también a las formas de producirlo relacionadas con la industria de los soportes digitales.

Los géneros de la LIJ siguen siendo los mismos, el paradigma radica en la inclusión de nuevos objetos, los distintos elementos multimedia que aportan un valor único a la lectura y al texto, y el formato y el soporte, que imprimen las características propias; pues los libros app necesitan los sistemas operativos y los dispositivos de lectura para poder existir.

En este campo, los desarrolladores se decantan por el sistema iOS, pero se están dando cuenta de la importancia de crear sus productos también en Android para cubrir toda la demanda y abarcar nuevos y potenciales clientes.

En lo que respecta a las edades lectoras, se conservan los mismos parámetros del subsector LIJ, aunque despunta la predilección por la creación de libros app prelectores e infantil frente a la producción para jóvenes.

Los libros app infantiles y juveniles tienen un precio inferior a los libros en papel debido a la perspectiva generalizada en la sociedad de que el contenido digital debe costar menos al modificarse los preceptos culturales sobre la descarga y la propiedad.

Junto a la transformación en el sistema productivo, la mayor variación en el modelo de negocio procede de la comercialización y la transformación de los canales de distribución. Si antes la industria editorial necesitaba la intermediación para llegar a los clientes, la edición digital ha permitido desintermediar el proceso de distribución y apostar bien por las plataformas creadas por los desarrolladores, bien por la venta directa desde sus páginas web o por utilizar plataformas genéricas vinculadas a la industria de las TIC's.

Las compañías se centran en las plataformas de las empresas dedicadas a los dispositivos de lectura, como son iTunes y Google Play, porque están vinculadas a los sistemas operativos iOS y Android, o los canales con mayor proyección internacional en la comercialización de contenidos digitales, como Amazon.

En lo que respecta a la promoción, las firmas siguen acudiendo a eventos especializados, pues estos acontecimientos les acercan a sus clientes y porque son lugares de intercambio de ideas y debate. Pero también han visto la oportunidad que brindan las herramientas Social Media, especialmente las redes sociales y los blogs, para difundir, promocionar y aportar información, tanto de su compañía como de sus productos, e interactuar con los clientes y/o lectores u otros desarrolladores para establecer proyectos colaborativos. 
Por lo que ser refiere a las perspectivas de futuro la valoración general es positiva, y la mayoría de las empresas consideran que los lectores infantiles y juveniles son un mercado con gran potencial. Se ven a si mismas como compañías creativas e innovadoras que apuestan por la calidad de los productos y por la transformación del subsector LIJ, lo cual puede conllevar a su proyección internacional y hacer que la edición digital en España se posicione a nivel mundial.

\section{NOTAS}

${ }^{1}$ La edición digital de LIJ en España despega en el año 2008, por lo que no es hasta años subsiguientes cuando la producción, distribución y comercialización de los libros electrónicos para niños y jóvenes aumenta. Es en el año 2010 cuando comienza a producirse el crecimiento exponencial de la edición digital de LIJ, alcanzando en el año 2012 su mayor porcentaje.

${ }^{2}$ A raíz del surgimiento, expansión e instauración de la tecnología en la literatura y la edición, la investigación en España se ha centrado en estudios, infografías e informes sobre libros electrónicos, producción, distribución y consumo de eBooks y dispositivos de lectura. Sobre el mercado de libros electrónicos, los estudios, principalmente del Observatorio de la Lectura y el Libro, se han centrado en los canales de distribución y las técnicas de marketing y cómo éstas nuevas plataformas y herramientas están transformando la industria editorial; pero en las publicaciones también se habla de la producción, es decir, de las cifras de venta de eBooks, como señalan, por ejemplo, los informes del Laboratorio de ideas sobre el libro. Asimismo, se trabaja intensamente en el contenido de los libros electrónicos, sus formatos y sus soportes, estos aspectos han sido tratados especialmente por el grupo E-lectra, especialmente por el profesor CORDÓN GARCÍA, en diversas monografías, con capítulos distintivos sobre los dispositivos de lectura, los formatos y estándares de conversión y los contenidos de los eBooks, incluyendo los contenidos digitales del subsector LIJ. En este sentido, el grupo ha llevado a cabo un estudio que versa sobre la creación de sistemas de selección y evaluación de libros digitales, incluyendo los libros electrónicos con contenido multimedia. Todas estas obras han sido consultadas para la elaboración de este artículo y están incluidas en la bibliografía.

${ }^{3}$ Definición tomada de: Gómez Díaz, R. y Cordón García, J.A. Aplicaciones de lectura. DINLE: Diccionario Digital de Nuevas Formas de Lectura y Escritura. Universidad de Salamanca. Red Internacional de Universidades Lectoras. <http://dinle.usal.es/searchword.php?valor=Aplicaciones de lectura>.

${ }^{4}$ Edita Interactiva es la Asociación de editores digitales españoles de contenido infantil e interactivo. <http://www.editainteractiva.com/>.

5 Por perfil profesional "tradicional" debe entenderse los puestos de trabajo y funciones creados, desarrollados y desempeñados habitualmente en las editoriales en comparación con los perfiles profesionales característicos de los desarrolladores de libros apps infantiles y juveniles que han sido creados y desarrollados ex profeso, o integrados desde otras disciplinas, en el entorno de la edición digital e internet.

${ }^{6}$ Playtales es una aplicación de lectura compartida, creada como proyecto colaborativo entre varios desarrolladores, que incorpora una librería de cuentos interactivos para niños basados no sólo en el entretenimiento sino también en el aprendizaje de gramática, vocabulario o idiomas. $<$ http://www.playtalesbooks.com/es/>.

${ }^{7}$ Según Marc Prensky se entiende por nativos digitales “[...] la generación formada en los nuevos avances tecnológicos, a los que se han acostumbrado por inmersión al encontrarse, desde siempre, rodeados de ordenadores, vídeos y videojuegos, música digital, telefonía móvil y otros entretenimientos y herramientas afines". (Prensky, 2001, p. 5).

\section{BIBLIOGRAFÍA.}

ALONSO ARÉVALO, J. Niños y medios de comunicación en los Estados Unidos. [Post] [En línea] Blog Universo Abierto, 2012. Disponible en: <http://www.universoabierto.com/7382/ninos-y-medios-de-comunicacion-en-losestados-unidos/> [Consulta: 4 de junio de 2013].

AMETIC. Informe de la industria de contenidos digitales 2011. [En línea] Madrid, 2011. Disponible en: <http://www.cedro.org/docs/documentos/informe_contenidosdigitales2011.pdf> [Consulta: 13 de mayo de 2013].

ANATOMÍA DE LA EDICIÓN. El laboratorio de ideas sobre el libro. [Web] [En línea] Anatomía de la edición: Estudios sobre el sector editorial, 2012. Disponible en: <http://laboratoriodellibro.com/> [Consulta: 10 de junio de 2013].

APTARA PW. The fourth anual eBook survey of publishers. [En línea] Aptara PW, abril 2012. Disponible en: <http://ww3.aptaracorp.com/lp/landingpages/4thebooksurveyregister.html> [Consulta: 16 de mayo de 2013].

ÁVILA ÁlvAREZ, A.M. El libro electrónico. [En línea] Boletín Económico del ICE, no 2978, 2009 , p. 13 - 22. Disponible en: <http://www.revistasice.com/cachepdf/BICE_2978_1322_0265C30C37F5ED1B176B22EC57E8E818.pdf> [Consulta: 14 de mayo de 2013].

BORRELL, M. Plataformas de comercialización de libros electrónicos. En Libros electrónicos y contenidos digitales en la sociedad del conocimiento: mercado, servicios y derechos. Madrid: Pirámide, 2012, p. 107-128.

CABRERA, J. Ebooks infantiles. [Blog] [En línea]. Disponible en: <http://ebooksinfantiles.wordpress.com/> [Consulta: 5 de junio de 2013].

CAMERON, P. (coord.). Booktrack: soundtracks for books. [App] [En línea] Booktrack, 2013. Disponible en: <http://www.booktrack.com/> [Consulta: 10 de junio de 2013].

CORDÓN GARCÍA, J.A. et al. Análisis y evaluación de programas de lectura e análisis investigación en dispositivos móviles: apps, lectura social y aplicaciones 2.0. Memoria de resultados del proyecto de innovación. [En línea] Grupo E-lectra: Universidad de Salamanca, 2012. Disponible en: <http://gredos.usal.es/jspui/bitstream/10366/120491/1/MID_11_044.pdf> [Consulta: 15 de mayo de 2013]. 
CORDÓN GARCÍA, J.A.; GÓMEZ DÍAZ, R. y ALONSO ARÉVALO, J. Gutenberg 2.0: la revolución de los libros electrónicos. Gijón: Trea, 2011.

CORDÓN GARCÍA, J.A.; ALONSO ARÉVALO, J y MARTÍN RODERO, H. Los libros electrónicos: la tercera ola de la revolución digital. [En línea] Anales de Documentación, 2010, vol. 13, p. 53-80. Disponible en: <http://revistas.um.es/analesdoc/article/view/106991/101681> [Consulta: 14 de mayo de 2013].

CORDÓN GARCÍA, J.A. La revolución del libro electrónico. Barcelona: UOC, Trea, 2011.

CORDÓN GARCÍA, J.A. (coord.). Libros electrónicos y contenidos digitales en la sociedad del conocimiento: mercado, servicios y derechos. Madrid: Pirámide, 2012.

FEDERACIÓN DE GREMIOS DE EDITORES ESPAÑOLES. Hábitos de lectura y compra de libros en España en 2012. [En línea] Conecta, enero $2013 . \quad$ Disponible en: <http://www.federacioneditores.org/0_Resources/Documentos/HabitosLecturaCompraLibros2012ESP_310113_1. pdf> [Consulta: 13 de mayo de 2013].

FEDERACIÓN DE GREMIOS DE EDITORES ESPAÑOLES. $2^{a}$ encuesta sobre el libro digital en España. [En línea] Neturity, marzo $2011 . \quad$ Disponible en: <http://www.dilve.es/dilve/getArchivoDocumentacion.do?iddocumento=1541> [Consulta: 13 de mayo de 2013].

FUNDACIÓN GERMÁN SÁNCHEZ RUIPÉREZ. eBook-18. Los lectores niños y jóvenes y libros electrónicos. [En línea] Colección La voz de los e-Lectores: Territorio eBook, Peñaranda de Bracamonte, 2012. Disponible en: <http://www.territorioebook.com/recursos/vozelectores/menos18/informe_lectores_menos_18.pdf> [Consulta: 15 de mayo de 2013].

GARCÍA RODRÍGUEZ, A. Diagnóstico del mercado de contenidos digitales infantiles y juveniles en España. En Libros electrónicos y contenidos digitales en la sociedad del conocimiento: mercado, servicios y derechos. Madrid: Pirámide, 2012.

GARCÍA RODRÍGUEZ, A. El papel de las plataformas de distribución y venta en la promoción de libros electrónicos infantiles y juveniles. [En línea] Anales de documentación, 2013, vol. 16, $\mathrm{n}^{\circ} 1$ Disponible en: $<$ http://dx.doi.org/10.6018/analesdoc.16.1.166601> [Consulta: 14 de mayo de 2013].

GARCÍA RODRÍGUEZ, A.; GÓMEZ DÍAZ, R. y CORDÓN GARCÍA, J.A. De Alicia en el país de las maravillas a las "maravillas de Alicia": de la selección de libros infantiles y juvenil en papel a la de los libros electrónicos. Revista Ibersid, 2013, vol.16, p. 21-32. Disponible en: <http://www.ibersid.eu/ojs/index.php/ibersid/> [Consulta: 18 de noviembre de 2013].

GENERALITAT DE CATALUNYA. Lectura en digital. [En línea] Col.lecció TAC-5: Department d' Ensenyament, diciembre 2012. Disponible en: <http://www20.gencat.cat/docs/Educacio/Home/Departament/Publicacions/Col_leccions/TAC/lectura_digital_TA C_5/TAC_5.pdf> [Consulta: 14 de junio de 2013].

GÓMEZ SOTO, J. Literatura infantil y juvenil actual. [Blog] [En línea] Disponible en: <http://lijjg.blogspot.com.es/> [Consulta: 3 de junio de 2013].

ICEX. Oportunidades de distribución digital internacional para el sector editorial. [En línea] Ministerio de Economía y Competitividad, Madrid, febrero de 2012. Disponible en: <http://www.icex.es/icex/cma/contentTypes/common/records/mostrarDocumento/?doc=456481> [Consulta: $12 \mathrm{de}$ mayo de 2013].

INNODATA. Device and platform prioritization. A methodology for determining which tablet or mobile platforms to prioritize when seeking to monetize content through new channels. [En línea] INNODATA. Disponible en: <http://www.innodata.com/resources/white_papers> [Consulta: 18 de junio de 2013].

INTERACTIVE ADVERTISING BUREAU. IV Estudio anual redes sociales. [En línea] Elogia Marketing 4 ecommerce, Madrid, enero 2013 Disponible en: <http://www.iabspain.net/wpcontent/uploads/downloads/2013/01/IV-estudio-anual-RRSS_reducida.pdf> [Consulta: 17 de junio de 2013].

KOBO. The Children's Digital Book Market. The future looks bright. [En línea] Kobo, Spring 2013. Disponible en: $<$ https://media.kobobooks.com/sites/media.kobobooks.com/files/documents/childrens_digital_book_market__kobo_white_paper_spring_2013.pdf> [Consulta: 10 de julio de 2013].

LABORATORIO DE IDEAS SOBRE EL LIBRO. La gran transformación. Panorama del sector del libro 20122015. [En línea] Anatomía de la edición: Madrid, 2012. Disponible en: <http://laboratoriodellibro.com/project/lagran-transformacion/> [Consulta: 16 de mayo de 2013].

LABORATORIO DE IDEAS SOBRE EL LIBRO. Primera oleada sobre el panorama del libro en España. Informe 2013. [En línea] Anatomía de la edición: Madrid, 2013 Disponible en: <http://laboratoriodellibro.com/project/informe-primera-oleada-sobre-el-panorama-del-sector-del-libro-enespana/> [Consulta: 14 de junio de 2013].

LÓPEZ MUÑ̃Z, L. (coord.). Los contenidos digitales en España. Informe Anual 2011. [En línea] ed. 2012 : ONTSI. Disponible en: <http://www.ontsi.red.es/ontsi/sites/default/files/informe_contenidos_digitales_edicion2012.pdf> [Consulta: 10 de julio de 2013]. 
MINISTERIO DE CULTURA. Los libros infantiles y juveniles. [En línea] Ministerio de Cultura, España, 2006. Disponible en: <http://www.mcu.es/libro/docs/MC/CD/EstSobreSector1.pdf> [Consulta: 13 de mayo de 2013].

OBSERVATORIO DE LA LECTURA Y EL LIBRO. Los libros infantiles y juveniles. [En línea] Ministerio de Educación, Cultura y Deporte, España, marzo de 2012. Disponible en: <http://www.mcu.es/libro/docs/MC/Observatorio/pdf/2010_LIJ.pdf> [Consulta: 12 de mayo de 2013].

OBSERVATORIO DE LA LECTURA Y EL LIBRO. Panorámica de la edición española de libros 2012: análisis sectorial del libro. Secretaría General Técnica. Centro de Publicaciones. Ministerio de Educación, Cultura y Deporte, España, 2013. Disponible en: 〈https://sede.educacion.gob.es/publiventa/detalle.action?cod=14452C〉 [Consulta: 20 de enero de 2014].

PRENSKY, M. Digital natives, Digital inmigrants. [En línea] En On the horizon. MCB University Press, vol. 9, nº 5, octubre $2001 \quad$ Disponible en: <http://www.marcprensky.com/writing/Prensky\%20\%20Digital\%20Natives,\%20Digital\%20Immigrants\%20-\%20Part1.pdf> [Consulta: 15 de mayo de 2013].

SCM WORLD. Amazon beats Apple in a battle for supply chain leadership. [En línea] 2012. Disponible en: $<$ http://www.scmworld.com/communitynews/amazon-beats-apple-in-battle-for-supply-chain-leadership/> [Consulta: 18 de mayo de 2013].

VÁZQUEZ, J.A. y CELAYA, J. Cronología de la edición digital (1912-2012). [En línea] Dosdoce.com. Disponible en: <http://www.dosdoce.com/articulo/estudios/3725/edicion-digital/> [Consulta: 18 de mayo de 2013].

WEBTOOLS. e-Encuesta. [Software] [En línea] Madrid, 2006-2013. Disponible en: <http://www.eencuesta.com/index.do?gclid=CLKujoDh97gCFU1f3god5jcAsA> [Consulta: 10 de abril de 2013]. 